\title{
How prosody reflects semantic change: a syn- chronic case study of of course
}

\author{
Anne Wichmann, Anne-Marie Simon-Vandenbergen, \\ Karin Aijmer
}

\section{Introduction}

Discourse markers (DMs) have recently received a fair amount of linguistic attention, both from synchronic and diachronic perspectives, in a range of languages as well as across languages in contrastive studies (see e.g. two recently published edited volumes, Fischer 2006, Aijmer and SimonVandenbergen 2006). However, one aspect which has received little attention in this area is the prosodic realisation of discourse markers. Since they are generally accepted to be more typical of spoken than of written language (Brinton 1996), the neglect of this aspect is regrettable.

In this article we have two aims. One is to provide a detailed description of the functions and prosodic realisations of of course in presentday spoken British English (PDE), on the basis of corpus data. How of course functions in spoken language is an interesting question in itself, since it appears to be an extremely frequent phrase (see SimonVandenbergen and Aijmer 2002/2003, Note 1). With the analysis we want to answer the question to what extent of course fulfils the criteria for discourse marker status. On a more general level, however, we aim to contribute to the discussion on the relation between grammaticalisation and prosody.

\section{Discourse markers}

\subsection{Discourse markers and grammaticalisation}

Before we can begin to examine the question of the status of of course in PDE it is necessary to take a position with regard to the status of the historical changes which generally lead to the emergence of the class of discourse markers. Even though we do not engage in a diachronic study, we 
will show that the various uses of of course in PDE reflect varying degrees of closeness to and distance from its earlier meaning as a fully lexical item and that these degrees can be related to a decrease of semantic weight and a correlated increase of pragmatic functions. This means that the variation we find in PDE partly reflects past and perhaps ongoing change which must be accounted for by reference to what we know about similar changes in other adverbs.

The question of the status of the development into DMs has been answered in four different ways. The four ways are extensively discussed by Traugott (1997 [1995]) and we shall not repeat the arguments for and against the positions here. Suffice it to say that the positions are lexicalisation, pragmaticalisation, grammaticalisation and post-grammaticalisation. The reason why there is disagreement over how to label these developments is that there is disagreement over the necessary conditions for talking about grammaticalisation. As Traugott explains, those who want to exclude DMs from grammaticalisation argue that they are not grammatical items, and that they do not fulfil what are seen as certain essential criteria such as reduction in scope and fixation, criteria given by Lehmann (1995: 164). In fact, DMs show the opposite tendency, namely an increase in scope and a looser syntactic connection to the rest of the sentence. So, as Traugott points out, if we want to claim that DMs are the result of processes of grammaticalisation we have to rethink the criteria of grammaticalisation as well as the nature of the grammar (Traugott 1997: 5 [1995]).

Traugott argues that of the four solutions proposed in the literature, grammaticalisation is the most appealing one. Pragmaticalisation, which has been proposed by Erman and Kotsinas (1993) for cases such as you know, captures the increase in pragmatic functions which such items have gained in the course of their development but the concept does not satisfactorily account for formal and structural changes. 'Pragmatic strengthening' (Traugott 1989) is a concomitant feature of grammaticalisation but it does not explain the whole process. We follow Traugott in opting for the term 'grammaticalisation' in spite of the need to relax some of the criteria. The reasons are briefly summed up below (for a more extensive account, see Traugott 1997 [1995]).

DMs typically develop from lexical material into items which serve grammatical functions and which occur in well-defined syntactic slots. The development entails desemanticisation and increasing pragmaticalisation. Typically DMs move to the left periphery of the sentence and acquire new meanings, new syntactic constraints and new prosodic characteristics. The 
typical diachronic path is described by Traugott (1997: 13 [1995]) as follows:

verbal adverb $>$ sentential adverb $>$ discourse marker

The development into a DM is, as pointed out by Traugott, accompanied by a number of shifts "normally associated with grammaticalisation" (1997: 13-14 [1995]). Traugott mentions six shifts and shows how these have taken place in the instances under consideration, indeed, in fact and besides. These shifts are (i) decategorialisation (the lexical nouns deed, fact, side become fixed in prepositional phrases), (ii) bonding within the phrase (bonding with the prepositions in and by), (iii) phonological reduction (which is possible though not always realised), (iv) generalisation of meaning (increase of polysemies), (v) increase in pragmatic function (concrete > epistemic > metatextual elaborator), (vi) subjectification (increasing association with speaker attitude). The problem areas for the grammaticalisation stance are scope and disjunction. In contrast with 'typical' cases of grammaticalisation (e.g. Lehmann 1995: 143), DMs do not have a reduced but an increased scope, and they do not come to occupy fixed syntactic slots in the sense that, say, clitics do. Traugott's arguments are that "syntactic scope increases must be allowed for in a theory of grammaticalisation" and that the disjunct slot occupied by DMs can be considered as "the typical syntactic site" to which items move in the process in languages such as English. Other languages such as German reserve the middle field for discourse particles with similar functions to DMs (Traugott 1997: 14 [1995]; see also Diewald (2006), discussed below).

If we accept - as we do - that from a formal and structural point of view DMs are instances of grammaticalisation, this still leaves us with the question of whether they indeed fulfil 'grammatical' functions. Traugott's position is the following:

"The view of grammar adopted here is that it structures cognitive and communicative aspects of language. It encompasses not only phonology, morphosyntax and semantics but also inferences that arise out of linguistic form, in other words, linguistic pragmatics such as topicalisation, deixis." (Traugott 1997: 5 [1995]) 
In the same vein, Diewald (2006: 405) writes that the pragmatic functions that DMs ${ }^{1}$ have are "genuine grammatical functions which are indispensable for the organisation and structuring of spoken dialogic discourse." She, too, rejects the distinction 'pragmaticalisation vs. grammaticalisation' in favour of a view of grammar which includes discourse structuring elements. Diewald refers to various arguments given in the literature to support the 'DMs as grammaticalisation view', including Günthner (1999), Barth and Couper-Kuhlen (2002), Lima (2002). Diewald (2006: 408) also sees DMs as syntactically non-integrated. This syntactic non-integration, in the sense that DMs have no syntactically fixed position, distinguishes them from modal particles, which appear in the middle field. In Diewald's view, the functional criteria are primary and are valid cross-linguistically, while the formal and structural ones may well be language specific (2006: 408). With regard to the question whether DMs have an inherent semantic meaning which plays a role in the pragmatics, Diewald's answer is 'yes'. She postulates a 'core meaning' which is present in all the uses of the DM and the "synchronic polyfunctionality of the particle [including DM] lexemes is due to the reinterpretation of the basic semantic template" (Diewald 2006: 405). We share this view, as shown in Section 6 (see 6.1 and 6.2).

The semantic development traceable for DMs follows the tendencies generally attested as typical of grammaticalisation. These tendencies have been described as metaphorisation from concrete to more abstract (Heine, Claudi and Hünenmeyer 1991), for example typically along the following path:

local $>$ temporal $>$ abstract (e.g. causal; adversative, copulative)

(Diewald 2006: 410)

In addition, Traugott distinguishes three recurrent diachronic stages (1989: 34-35) typical of the development of DMs, which are well-known and need not be further discussed: the functional development from meanings based in the external situation to meanings based in the textual situation to meanings increasingly based in the speaker's subjective belief. This scheme was later refined (e.g. Traugott and Dasher 2002) to include the further step

\footnotetext{
${ }^{1}$ Diewald (2006) actually uses the term discourse particles instead of discourse markers and distinguishes them from modal particles. In the discussion of Diewald's position we shall, however, keep using the term discourse marker for the sake of consistency.
} 
from subjectification to intersubjectification, to account for social deixis (e.g. for such functions as the expression of politeness or solidarity).

DMs have by definition a discourse function, which entails indexing the utterances to the surrounding discourse, both in terms of structuring the ongoing discourse and in terms of signalling to the addressee how he/she should interpret the speaker's stance. Aijmer, Foolen and SimonVandenbergen (2006) mention three functions as important in this respect: reflexivity (metacommunicative function), indexicality (pointing to the speaker's position with regard to persons and situations) and heteroglossia (positioning the speaker's voice within a context of other voices, see e.g. White 2003 for an account). These functions are all non-propositional and abstract.

Summing up, there are cogent reasons for considering the development of DMs as one of grammaticalisation, and it is the purpose of this article to examine the extent to which of course in PDE is a DM according to the generally accepted criteria prosody, discourse function and semantic change.

\subsection{The prosody of discourse markers}

\subsubsection{Previous studies: inconclusive results}

Despite numerous claims in the literature that prosodic features contribute to the identity of discourse markers, there is to date no comprehensive overview of what these features are and how they operate. Early quantitative studies based on corpus data (Meyer 1986, Altenberg, 1987, 1990; Stenström 1990) are inconclusive. They are in fact studies of the prosodic behaviour of the broad class of 'adverbials', but the definition of adverbials follows the categories of Quirk et al. (1985), which include 'disjuncts', and 'conjuncts', both of which categories contain items that we would now refer to as discourse markers. Stenström points out, rightly, that adverbials are distinguished prosodically not only by segmentation (presence or absence of a boundary) but also by tonicity (presence or absence of nuclear tone) and by tonality (choice of tone). Nonetheless, the generalisations offered are more a matter of expedience for text-to-speech systems than linguistically revealing. Altenberg concludes that prediction rules (i.e. for text-to-speech synthesis) for adverbials are complicated by 'their formal and functional diversity' (1990: 283). 
The reason for variable prosodic patterning may in part be morphological. There seems to be some agreement, for example, that the longer and more complex the adverbial, the more likely it is to be punctuated (and prosodically separate). According to Altenberg, "initial adverbials, which generally have a grounding, connective or attitudinal function (as adjuncts, conjuncts or disjuncts), are normally set off in a separate tone unit if they are polysyllabic."(1990: 283-4). Speed of delivery also plays a part - the slower the delivery, the more likely a tone unit boundary. This of course is in part determined by the context of situation, which constrains speech style (e.g. formal - informal, dialogue - monologue, prepared - spontaneous), and in turn constrains aspects of articulation, e.g. tempo, degrees of reduction and other connected speech processes.

More recently there have been studies of the prosody of individual discourse markers (in English: you know (Holmes 1986), well (Bolinger 1989), now (Hirschberg and Litman 1993), anyway (Ferrara 1997, see also Wennerstrom 2001); in Swedish: men (Horne et al. 2001) The results have identified more nuances than in earlier studies, but there is still no clearer view of the extent to which discourse markers exhibit unique sets of prosodic patterns. We are left with an incomplete picture of what to expect prosodically of discourse markers, making it difficult in turn to use prosodic features to identify function in cases of ambiguity.

We believe nonetheless that it is possible to identify a number of patterns that systematically co-occur with discourse markers, and we will argue that these are underpinned by the processes of lexical change. This argument is based firstly on the fact that discourse markers share functions with other grammatical classes, and secondly on a theory of intonational meaning that relates propositional content to prosodic prominence.

\subsubsection{Prosody and discourse function}

The extreme variability reported by e.g. Stenström is the result of generalisation on the basis of lexical items (which a speech synthesiser can identify) rather than on the basis of discourse functions (which it cannot). If we re-analyse Stenström's findings according to individual subcategories of adverb in the London Lund Corpus (1990: 261), we find greater systematicity. All 'disjuncts' (they include epistemic stance adverbs e.g. apparently, of course, clearly, fortunately) are prosodically separate in her data, with either a falling tone or a fall-rise. The distribution of these tones is not given, but may be consistent with Cruttenden's observation that "ad- 
verbials which limit the main clause take a rise, while those that reinforce take a fall" (1997: 95). 'Conjuncts' (adverbials with a connective func$\operatorname{tion}^{2}$ ), on the other hand, are either separate with a falling tone, or unstressed and integrated. The distribution is not given. Thus we would predict (invented examples):

Disjuncts / stance adverbials

$$
\begin{aligned}
& A \bigvee \text { pparently } \mid \text { he's not coming after } \backslash \text { all } \|^{3} \\
& \text { Or } \\
& \backslash \text { Certainly } \mid \text { we're going to have to \deal with this } \|
\end{aligned}
$$

Conjuncts/ discourse markers

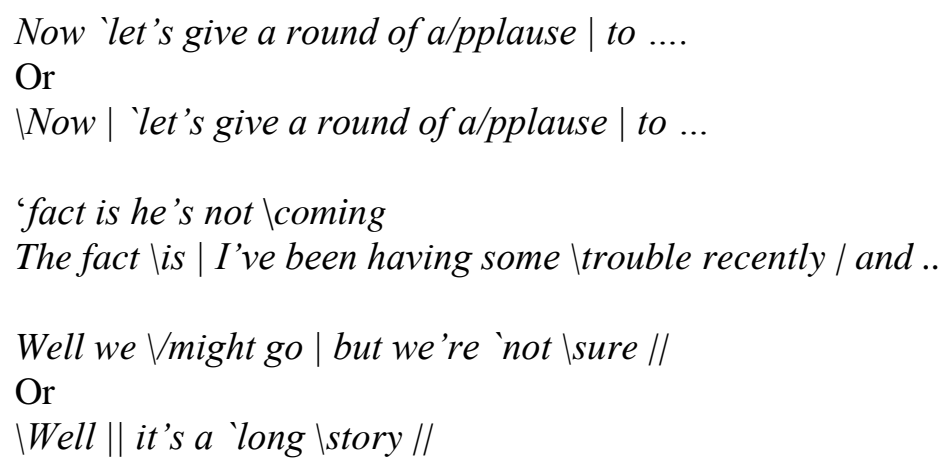

Intheir unstressed form, these conjuncts behave just like other grammatical conjunctions (because, and etc). In their stressed form, however, they behave as other grammatical elements do, whether NP, adverbial or main clause, when a new topic or title is being announced - namely by treating

\footnotetext{
${ }^{2}$ It is therefore not surprising that the same prosodic patterns can be found on 'normal' conjunctions (co-ordinating, subordinating). The idea that discourse particles can have uses in common with other grammatical categories has been noted by Aijmer (2002: 27).

${ }^{3}$ The prosodic symbols throughout are based on those used in the British system of intonation. The $\backslash$ indicates a falling pitch contour, associated with an accented syllable and any unstressed material up to the next accent or a boundary. The / indicates a rising contour, and the Vindicates a falling-rising contour. This is marked before the accented syllable on which the contour begins, but the rising part of the contour may occur on subsequent unstressed material. The symbols | and || represent minor and major tone group boundaries. The symbol 'indicates the first accent in a tone group (normally the 'onset').
} 
the item as a complete utterance (cf. Wichmann 1998). The effect is to widen the scope of the conjunct to relate to larger domains. This increased scope of conjuncts is a possibility that has already been noted by Quirk et al.:

“... conjuncts can relate units much larger than sentences: nonetheless at the beginning of a paragraph or section of a text will indicate a conjoining contrast with the whole preceding paragraph or section." (1985: $632 \mathrm{n}$ )

In speech, this phenomenon of linking across larger or smaller domains, is signalled by prosody. By assigning stress to a conjunctive DM, the size of the shift is exaggerated. The same effect is created by stressing a conjunction.

\subsubsection{How does this relate to semantic change and intonation theory?}

Because it is non-propositional, intonational meaning is elusive. Most accounts suggest very broad abstract meanings associated with pitch movements, such as 'finality' or 'non-finality', 'closed' or 'open' (Cruttenden 1997, Wichmann 2000). Because the meanings are so abstract, there is no one-to-one relationship between prosody and lexical item, or between prosody and word class. If a discourse marker is realised in a way typical of major shifts in the discourse, this is not the prosody of the discourse marker, it is the prosody of a major structural shift. If there is a tendency for certain co-occurrences, this is because there is tendency for certain words to be used for a particular discourse function, not because the prosody is the property of the word itself.

The theory of intonational meaning in English proposed by Pierrehumbert and Hirschberg (1990) tries to account not only for pitch movement (tone choice) but also for the effect of intonational prominence (presence or absence of an accented syllable). They claim that the degree of prosodic prominence is directly related to the informativeness or propositionality of the associated word or phrase. This accounts for the fact that in speech, lexical words have much greater potential for prominence (stress) than grammatical or function words. The theory of semantic change (see Section 2.1 above) proposes that, over time, certain high frequency items are subject to a gradual loss of semantic weight, a process of 'bleaching' through habituation, and acquire a grammatical or pragmatic role. Dis- 
course markers often derive, via this process, from verbal adverbs (see Section 3.2).

In line with the theory of intonational meaning, we can predict that this process of semantic change will go hand in hand with a loss of potential for prosodic prominence. Those items that have a purely interpersonal function, highly routinised and with very little residual core meaning, we would expect to be least prominent, while those that still express some propositional meaning, e.g. epistemic or evidential stance towards a proposition, might have greater prominence.

If it is possible to consider the distinction made by some grammarians between disjunct and conjunct (see also Section 3.1.1 below) to be a distinction between (subjectified) propositional meaning and discourse meaning, then we can predict that elements used as expressions of stance towards the proposition are more likely to be stressed than those used in a routinised way for cohesive or interpersonal purposes. This would account for the variability reported in earlier studies, given that they tried to generalise over a much broader category of adverbials. It would also account for the systematic realisation of subcategories of adverbials: Stenstrom's disjuncts are typical examples of elements which express stance towards the proposition and have obvious residual propositional meaning themselves. The conjuncts, however, behave frequently like other grammatical conjunctions - unstressed and integrated into a larger tone group. Confusion arises only when one of these conjuncts is stressed. While we don't confuse a stressed conjunction ( $\backslash$ And $|, \backslash B u t|$ ) with any other word class, but simply understand it as a 'bigger' and or but, a stressed conjunct (actually just a 'bigger' well, now or anyway, indicating a greater scope) is prosodically identical to a stressed stance adverbial, and if the same word functions as both, the prosody may introduce ambiguity. For this reason, it is not possible to use prominence alone to disambiguate the time adverb now from the conjunct now. The unstressed version - behaving normally as a grammatical word - is indeed more common, but an emphatic Wow $\|$ is not a time adverb but a conjunct with wider scope. 


\section{Of course: previous work}

\subsection{Of course in present-day English}

\subsubsection{The grammatical status of of course}

Of course is classified as an adverb in Quirk et al. (1985: 9.5), where it is to be found in the sections on subjuncts, disjuncts and conjuncts. As a subjunct, it is relatively integrated into the clause, occurring next to the clausal element it emphasises. Quirk et al. also make a comment on the prosodic features of subjuncts, saying that they are not separated intonationally. (1985: 584). However, the group of so-called 'emphasisers' to which of course as a subjunct belongs, "mainly consist of items that can also function as disjuncts expressing the comment that what is being said is true" (1985: 8.100). As a disjunct, of course occurs in the periphery of the clause, usually initially. Thirdly, Quirk et al. recognise a conjunct use of of course. Conjuncts, like disjuncts, have a "superordinate" role in the clause (i.e. they have wider scope), and are syntactically peripheral. In contrast with disjuncts, they have a linking function. Quirk et al. distinguish two conjunctive uses, or semantic subtypes, viz. as a 'resultative' and 'concessive' conjunct. These are illustrated by examples (3) and (4) respectively:

(3) She arrived late, gave answers in an offhand manner and of course displeased the interviewing panel. (Quirk et al. 1985: 8.140)

(4) Of course he's a bit lazy; all the same I'd like to give him the job. (Quirk et al. 1985: 8.141)

Summing up, Quirk et al. correlate different functions of of course with the different syntactic options (degrees of clausal integration), as well as with contextual factors which distinguish between disjunctive and conjunctive uses. Prosody is mentioned in passing, where it is claimed that subjuncts are not separated by intonation or punctuation. The fact that disjuncts are often followed by commas would seem to suggest that they are separated intonationally as well, though in the conjunctive uses illustrated by examples (3) and (4) above there is no comma and no comment on the prosody is made. In other words, prosodic realisation is not linked explicitly to syntactic status or semantic type. Quirk et al.'s classification is primarily based on position in the clause, disjuncts and conjuncts being mostly initial. 
Holmes (1988) uses the term pragmatic particle to characterise all uses of of course, regardless of the syntactic slot it occupies and in all contextual functions. Simon-Vandenbergen and Aijmer (2002/2003) take the same position and refer to of course as a pragmatic marker "in all its occurrences, regardless of its position, syntactic integration, prosody and realisation as a full or reduced form" (2002/2003: 20). Holmes does not mention the concept of grammaticalisation but states that "of course is a discourse particle or verbal filler like you know and I think" (1988: 49). She also mentions the phonologically reduced form of of course "in rapid or casual speech". Phonological reduction is, as pointed out (Section 3 above) a feature associated with grammaticalisation.

In sum, the grammatical status of of course has been given little attention in the literature. While Quirk et al. (1985) distinguish three grammatical types, the assignment of of course to one of these types is based on a mixture of positional and contextual criteria. Holmes (1988) and SimonVandenbergen and Aijmer (2002/2003) classify of course as a pragmatic particle/marker but base this classification purely on functional criteria. What is lacking at the moment is an account which brings together formal, structural and functional features. In Section 3.1.2 we give a brief survey of the functions as discussed in the literature, in Section 3.1.3 the scanty information on prosodic forms of of course is summarised.

\subsubsection{The meaning, functions and prosody of of course}

Both Holmes (1988) and Simon-Vandenbergen (1992) recognise a core meaning of of course which remains invariant in the different contextual functions. Holmes formulates this core meaning as "an overt signal that the speaker is assuming that the hearer accepts or is already familiar with the propositional content of her or his utterance, and functions to emphasise the validity of that content" (1988: 53). The definition in SimonVandenbergen (1992: 215) is very similar: “(...) of course combines the meanings of certainly ('there is no doubt that...'), which expresses a probability judgement, and naturally 'it was to be expected that'), which conveys a judgement on the extent to which something was expected". In other words, both studies see the meanings of certainty and expectation as part of the core. In addition to that core meaning, of course has various contextually determined pragmatic functions.

Holmes (1988) distinguishes two main functions which she labels "impersonal" and "confidential". These tend to occur in different registers, the 
former in formal and public discourse, the latter in casual and intimate discourse. The difference has to do with the nature of the content which is presented as shared and the reasons for presenting it as such. In the impersonal use, of course marks generally shared knowledge, while in the confidential use it marks knowledge shared by intimates. Both types of of course can also have politeness functions and can be used manipulatively. Basically, the impersonal type is authoritative and potentially patronising, while the confidential type signals solidarity and can act as a positive politeness device.

Simon-Vandenbergen (1992) also links types of functions with types of contexts. The study compares uses of of course in casual conversation and in political interviews, and the conclusions are comparable to Holmes's. While in both registers speakers use of course to mark shared knowledge, the interactional aims differ. The meanings may be 'everybody knows that...', 'we both know that...', 'I know what you are telling me', 'you know what I'm telling you', 'you should know what I'm telling you' (Simon-Vandenbergen 1992: 215). Politeness is also said to operate differently in different genres.

The manipulative uses of of course in political colloquy are the focus of attention in White, Simon-Vandenbergen and Aijmer (forthcoming). From a heteroglossic perspective, of course is seen as a strategy which is dialogic but at the same time restricts the possibility for disagreement by expressing consensus or "concurrence" (White 2003: 269). In political discourse it is further frequently used as a rhetorical 'put-down', signalling that the opponents' arguments are not impressive. The distinctive pragmatic functions as discussed in the literature provide a basis for the functional classification of the data in this study.

There is little specific reference in the literature to the prosody of of course. We are aware of only two main sources of comments, the first a passing mention by Halliday and Hasan (1976) in relation to cohesion, and the second in a detailed analysis of the meanings and uses of of course in New Zealand speech (Holmes 1988). In their very brief account of of course, Halliday and Hasan identify two prosodic realisations, stressed (in their terms 'tonic') or unstressed (in their terms 'reduced'). In each case, the meaning ascribed is related to shared knowledge ('you should have known that already'), rather than any epistemic meaning such as 'naturally', 'predictably'. We may therefore infer that Halliday and Hasan classify of course as a grammatical item (discourse marker), and not as a stance adverbial. In her detailed corpus-based analysis, Holmes takes more parameters into account than stress alone, describing the prosody of of course 
in terms of position in tone group, stress, and choice of pitch contours. She envisages both integrated and prosodically separate versions - a separate tone-unit containing a stressed syllable (rising or falling), or, in initial position, as an unstressed pre-head.

Despite the claims made above, our own data suggests that, just as the degree of syntactic integration is probably a matter of degree, there are also degrees of prosodic integration that make such categorical observations problematic.

"It is uncertain whether we should regard discourse markers as part of the clause of as extra-clausal units (as applies also to parentheticals in writing). It is probably correct to say that there are degrees of integration, as expressed by prosody and the type of orthographic marker. When there is clear prosodic or orthographic separation, they are best treated as independent nonclausal units." (Biber et al 1999: 140)

\subsection{The history of of course}

An account by Lewis (2003) of the historical development of of course shows that its meaning derives from a structure containing the noun 'course' (French/Middle English cours) meaning 'the path taken e.g. by a river', which coalesced with of and came to mean 'in the natural order of things', 'predictable' or 'to be expected' (OED). Early use shows that it functioned both as an adjective and as an adverb. Adjectival use was predicative and postmodifying, the latter persisting into the $19^{\text {th }}$ century.

$$
\begin{aligned}
& 1580 \begin{array}{l}
\text { The friendship between man and man as it is common so it } \\
\text { is of course (OED) } \\
1813 \text { 'You must give me leave to flatter myself, my dear cousin, } \\
\text { that your refusal of my addresses is merely words of } \\
\text { course. (Jane Austen: Pride and Prejudice) }
\end{array} \\
& 1862 \text {... a matter of course (OED) }
\end{aligned}
$$

In PDE this usage remains only in the fixed expression a matter of course. Until the $19^{\text {th }}$ century, of course was also used as an adverb:

1548 A thing which is graunted $[=$ granted $]$ of course $(\mathrm{OED})$ 
1813 'Mr Collins had only to change from Jane to Elizabeth and it was soon done - done while Mrs Bennett was stirring the fire. Elizabeth, equally next to Jane in birth and beauty, succeeded her of course.' (Jane Austen: Pride and Prejudice)

As a sentence-internal adverbial, of course appeared in the $17^{\text {th }}$ century meaning 'as usual' and underwent a further development in the $18^{\text {th }}$ century to a sentence adverbial ('in accordance with the natural ways of the world'):

1752 if a poor child is to be whipped equally for telling a lie, or for a snotty nose, he must of course think them equally criminal.' (cited in Lewis 2003)

By the end of the $19^{\text {th }}$ century of course has acquired a meta-textual, discourse-oriented function, pointing to a 'dispreferred argument, contrasting it with a preferred argument' (concession):

1885 'Of course, I am naturally a partial judge of my father's character; but this I may say, that during my experience of over seventy years I have never known a more incessantly industrious man' (Nasymygh, Autobiography, quoted from Lewis)

To sum up, the historical data show that the function of of course has changed over time, some usage now being obsolete, except in fixed expressions. The development is one from more lexical to more grammatical meaning, from more objective to more subjective which are the characteristics associated with grammaticalisation. The parallel with words such as in fact (Traugott 1997 [1995], discussed in Section 2.1 above) is obvious: it, too, started as a noun, became a fixed collocation with a preposition (coalescence), developed into a verbal adverb, and then acquired more subjective and discursive meanings. 


\section{Data and methodological considerations}

\subsection{The data}

This study of of course is based on naturally-occurring data taken from the International Corpus of English, British English (ICE GB) compiled at the Survey of English usage at University College London (Nelson, Wallis \& Aarts 2002). The value of this particular corpus is that the sound files are linked to the text, and can be accessed directly, meaning that sections of text, resulting from an automatic search and displayed on screen, can be listened to individually. The corpus contains 1 million words in all, of which 600,000 words are (transcribed) speech. This study is based on 200 examples of of course taken from a total of 552 occurrences in the spoken section of the corpus. As the corpus contains a variety of speech genres, the examples are taken to represent both dialogue and monologue, and different degrees of formality across those two broad dimensions. The dialogue examples (102) thus include both informal conversation (50) and dialogue in a public setting (50) (e.g. broadcast interviews), while the monologue section includes highly prepared or scripted speech (41) (e.g. broadcast talks) and more informal spontaneous speech (57) (e.g. spontaneous commentary). The tokens in dialogue were selected to represent as many text types as possible, and in cases where there were more tokens than needed, starting at the beginning of the group of texts, excluding inaudible examples, until an appropriate number had been collected. There was no selection other than for quality).

\subsection{Analysis}

The sound files were analysed auditorily by the first author ${ }^{4}$ and the text samples were prosodically annotated. For each token the accentual status (stressed, unstressed or indeterminate) was noted. The tokens were also categorised according to their position in a tone group, and then according to the pitch contours associated with stressed tokens (fall, fall-rise, rise

\footnotetext{
${ }^{4}$ Instrumental analysis is not possible for all of the tokens, given the noisiness of much speech collected in natural surroundings. In any case, extracted pitch contours (more properly F0 contours) cannot replace an auditory analysis of this kind.since speech software is unable to identify phonological categories such as pitch accents (AM system) or falls, rises etc (British system).
} 
etc). Each token was then categorised as being prosodically integrated or separate, with indeterminate cases marked as such in a third category.

All examples were examined in context for their semantic content (see Section 6.2). We assume that of course retains in all cases some core meaning, but that each example will be at a different point on a transparency scale. We found examples with a clear meaning of 'naturally' or 'the natural course of things' at one end of the scale, and at the other end we found examples signalling shared knowledge (you/we know this) where little of the core meaning remained. Inevitably there were many where both meanings co-existed or that were difficult to determine, and these were categorised separately. We thus had three broad levels of meaning: (1) epistemic/evidential - glossed as 'naturally'), (2) interpersonal - glossed as 'shared knowledge' (3) indeterminate.

In addition to the semantic and prosodic analysis, the tokens were annotated for their syntactic position, initial, medial or final, and for common collocates (e.g. but + of course, and + of course; see Section 5).

\section{Structural patterning of of course}

\subsection{Utterance positions}

Of course occurs in various positions in the utterance, which can be roughly described as initial, medial and final. Table 1 gives an overview of the frequency of each of these positions in the data.

Table 1. Utterance positions of of course.

\begin{tabular}{llll}
\hline initial & medial & final & total \\
\hline $101(50.5 \%)$ & $72(36 \%)$ & $27(13.5 \%)$ & 200 \\
\hline
\end{tabular}

Table 1 shows that initial position occurs in just over half the cases. It should be noted that cases where of course follows a conjunction (such as but of course, and of course) or a discourse marker (such as well of course, further of course) are also counted as initial because such conjunctions and discourse markers take obligatory initial position and thus force of course into second position in the utterance. Both elements must be considered as part of the thematic material (see Section 4.4 for a definition of Theme) in such cases (Thompson 2004 [1996]: 157). A comparison with the results reported by Holmes (1988: 51) shows that the general trends are the same: initial position is by far the most frequent one, followed by medial posi- 
tion, and then final position. The difference is that Holmes found an even higher percentage of initial instances $(60 \%$ in her New Zealand speech data, $86 \%$ in the British data). This difference may be due to the composition of the corpora. For instance, Holmes did not have any monologic data and the ICE-GB covers a wider range of genres. Holmes found a very different trend in written data, where medial position is most frequent.

The sample examined in this study further shows that in initial as well as in medial positions, of course recurs in a number of identifiable structural and pragmatic environments. In the following sections we take a closer look at the recurrent structural environments.

\subsection{Conjunction followed by of course}

Of course is frequently preceded by a conjunction, as Table 2 shows. The percentages are calculated on the total number of instances of initial of course (see Table 1):

Table 2. Frequency of of course in initial position preceded by and, but or a subordinating conjunction.

\begin{tabular}{llll}
\hline and of course & but of course & $\begin{array}{l}\text { subordinating con- } \\
\text { junction }+ \text { of course }\end{array}$ & total \\
\hline $35(34.5)$ & $15(15 \%)$ & $13(13 \%)$ & $63(62.5)$ \\
\hline
\end{tabular}

The figures show that in initial position of course occurs in combination with a conjunction in over $60 \%$ of the cases. In the total of 200 instances the combination accounts for nearly one in three cases. If such combinations are frequent they tell us something about the profile of of course. The combination but of course and the subordinating conjunctions (which are mostly contrastive/concessive) show the adversative functioning of of course (see Section 6.4 below). The combination with and, which is even more frequent, can have different functions. One is to flag that a piece of information which is self-evident is to follow, after the production of some not so evident information. Example (9) illustrates this.

(9) F: Well I have decided for a long time uh and the answer is I am very keen indeed to see Douglas Hurd as the next leader of the Conservative Party and the next Prime Minister E: Why 
F: Uh because he has had a considerable experience the most experience of any of the candidates in very high office

I saw him at work when I was in the Cabinet both in Northern Ireland where I had been before and of course at the Home Office where I had also been [broadcast news] <ICE-GB:S2B-009 \#62:1:F>

\subsection{Relative pronoun followed by of course}

Like conjunctions, relative pronouns take up obligatory first position in the clause, so that of course following a relative pronoun can also be classified as thematic. There are seven instances. Example (10) illustrates this position.

(10) They suddenly see it as a run up to another nineteen sixty-seven which of course was the great big set-back in modern Arab history when Israel emerged as a sort of imperial power and occupied large tracts of Arab territory which it s of course it still is it still holds [broadcast news] 〈ICE-GB:S2B-012 \#112:1:F>

The occurrence of of course in a relative clause enhances the backgrounding of the information: not only is it put in a syntactically subordinate clause but it is also presented as self-evident.

\subsection{Of course in post-thematic position}

One important medial position of of course is post-thematic. We are using the term Theme in the Hallidayan sense (Halliday and Matthiessen 2004: 64ff.) to refer to the first ideational element in the clause, possibly preceded by textual and interpersonal elements. It appears that of course occurs in post-thematic position in 29 instances, which accounts for $34.5 \%$ of all medial cases (14.5\% of all 200 instances in the database). Most frequent as themes are subjects and adverbials, which are unmarked and fairly unmarked themes respectively (Thompson 2004 [1996]: 144-145). A special type of subject preceding of course is the demonstrative pronoun, with an anaphoric function. The effect of of course in this position is that it highlights the theme, thus making it more prominent. Marking the thematic structure is one of the discourse functions that discourse markers typically 
fulfil (Diewald 2006: 406). Examples (11) and (12) illustrate of course following the thematic subject:

(11) Sadly Old Hushwing is no longer part of the great meadows of our countryside <,>

One of the problems of course is that the new agricultural methods have decreased grassland areas which were the birds ' feeding grounds <,> and removed the old barns and hollow trees in which they could roost and nest $<,>$ [broadcast talks] <ICE-GB:S2B-031 \#91:3:A>

(12) Now <,> the law <,>

Members of jury the first point is this <,>

This of course as you know is a civil case

it 's not a criminal case [legal presentations] <ICE-GB:S2A-061 \#56:1:A>

Of course also follows special thematic subjects which are attitudinal or metadiscursive comments such as it's very important of course..., the question of course....Thompson (1996: 152) refers to them as 'thematised comments'. They, too, receive extra focus in this way.

Another favoured position of of course (11 instances) is after the subject and the finite verb, or, in Hallidayan terms, after the Mood element (Halliday and Matthiessen 2004: $111 \mathrm{ff}$.). This is also a typical position of sentence adverbs and it has the same effect of highlighting as the postthematic one. Example (13) illustrates this.

(13) And Dick basically said he didn't like it because it was there were questions like were you given enough guidance and were your personal tutors good enough

And these are of course the the sort of questions that Dick doesn't really want answered because if someone says no the guidance wasn't good enough and our personal tutors weren't good enough then Neil 's going to say to Dick [direct conversations] <ICEGB:S1A-008 \#112:1:A>

\subsection{Of course in parenthetical remarks}

In parenthetical remarks of course enhances the backgrounding of the information because it presents it as 'known'. Examples are (14) and (15). 
(14) And the government thanks to the tax payers it represents of course coughs up a lot for various imperial ceremonies and functions <,> [broadcast talks] <ICE-GB:S2B-021 \#66:3:A>

(15) Her father is a man of incredible moral principle who will never do any work on a Sunday because it 's forbidden as he sees it in the Bible etc uhm

Exactly the sort of person that Rockefeller who also by the way of course is very religious but who he is going to trample underfoot and push out of the way [classroom lessons] <ICE-GB:S1B-005 \#21:1:A>

In (14) the parenthetical remark is thanks to the tax payers it represents of course, in which of course has final position. In (15), the parenthetical comment is who also by the way of course is very religious, in which of course occurs after the obligatorily initial relative pronoun and after the adverbial also and the discourse marker by the way. These examples show that of course can occupy different positions in parenthetical remarks

\subsection{Responses}

In responses of course is the new element which is given as a confirmatory answer to a polar question. In such contexts it is emphatic in comparison with a simple affirmative yes. Example (16) illustrates this use.

(16) R: Do you want him to become Prime Minister

S: Of course I do

I think it would be wonderful <,>

Yes

I'd be terribly proud of him

Wouldn't anybody <,> [broadcast news] <ICE-GB:S2B-003 \#135:1:S>

The reply Of course I do has only one element which is 'new' information, viz. the positive response to the polar question, signalled by of course. 


\section{The semantics and pragmatics of of course}

\subsection{Introduction}

The multifunctionality of of course in PDE is the result of its development from a full lexical item (prepositional phrase) into a sentence internal adverb, into a sentence adverb and finally into a discourse marker. Not only is it a characteristic of discourse markers that they are polysemous and multifunctional (see e.g. Aijmer 2000: 19 ff.), but it is also a characteristic of grammaticalised items that they exhibit what Hopper and Traugott (2003 [1993]: 49) refers to as 'layering' - the presence of different layers of meaning at the same time. This means that some of the former propositional meaning is still retained as a relic, while newly acquired meanings, some conventionalised, some as pragmatic inferences, are overlaid on the underlying meaning. The results are that the item occurs in different functions in different context, and that the different meanings of the polysemous item cannot always be sharply delineated. In some of its uses the item in question will have a meaning which is close to its propositional one, in other uses its meaning will be far removed from it, with a grey area in the middle, giving a cline of more lexical to more grammatical meanings, or more propositional to more textual or interpersonal ones.

In trying to grasp the multifunctionality of of course it has become clear to us that several factors play a role and that it is the interplay of all these factors that accounts for the complexity of its workings. The reason why of course is apparently, judging by its frequency, so useful, especially in speech, is precisely that it does very different things in different contexts, and its description must therefore be based on contextualised data. In the following sections we discuss the parameters which play a role in the semantic-pragmatic profile of of course. Four parameters are crucial for its description: its semantic meaning, its discourse status, its heteroglossic functioning, and the pragmatic stance it expresses.

\subsection{Semantic meaning}

The lexical meaning of of course 'as a natural consequence', (as in as a matter of course) is present in some of its occurrences. This sense is the epistemic-evidential sense, in which the speaker's assessment of the truth of the proposition is based on the fact that it follows as a natural result, and 
hence becomes inevitable. In this sense then of course has still a clear residue of lexical meaning. Here are some examples which illustrate this use.

D: The effects of nerve gas would be even worse

$\mathrm{E}$ : Well the nerve agents act basically by blocking the message from the nerves to the muscles so the muscles go into spasm and of course the muscles that control your breathing are in spasm and people asphyxiate and that can happen very quickly <,> [broadcast news] <ICE-GB:S2B-001 \#90:1:E>

In example (17) the propositions in the scope of of course are presented as the natural result of the preceding proposition that 'the muscles go into spasm'. A paraphrase 'as a result' would be possible in this case.

(18) A: You always read poetry presumably

B: Yes always

I lectured in English at Durham University and uh <,>

Well I studied English all my life so of course <,> I love poetry

Poetry 's lovely to read in bed at night

I think it uhm <,> it quietens your mind and $<,>$ flattens your spirit out [broadcast interviews] <ICE-GB:S1B-048 \#20:1:B>

In (18) also the proposition 'I love poetry' is presented as following naturally from the proposition 'I studied English all my life'. If an event is presented as following naturally from some other event or state-of-affairs, the mental step to the meaning that the event was or is predictable is a small one. In many contexts the paraphrase for of course is 'predictably'. The development is one from more objective to more subjective meaning, since it is people who make predictions and voice these. Example (19) illustrates this sense:

(19) Inside the medieval church is a sacred statue of the Marys sailing in a little wooden boat how they came to be here <,>

The legend tells us that after the crucifixion the two saints and their Egyptian servant Sarah were set adrift by the Jews of Jerusalem in a boat with no sails no oars and no food

But with the divine protection of the Lord the boat was guided ashore to the foot of the church walls <,>

Of course over the years the pilgrims have improved this story so that the boat contained Mary Magdalene Lazarus and his sister 
Martha and various other saints and the whole lot were greeted by Saint Trophemus <,,>

The reason that this is such a sacred place is because the two Marys remained in the Camargue with Sarah the servant and it is she who has become the most important person for the gypsies $<,>$

After her miraculous escape from the sea she wandered throughout the Mediterranean region and the gypsies identify with her nomadic existence and her life as an oppressed servant <,> [broadcast talks] <ICE-GB:S2B-027 \#111:1:A>

In (18) the proposition which is the 'cause' of the event modified by of course is not expressed, as was the case in (16) and (17) above. The proposition that 'over the years the pilgrims have improved this story' is nevertheless presented as somehow referring to something which 'took place in the natural course of events', which was predictable. The causing factor is left implicit because it is assumed to be known: the prediction is based on the speaker's knowledge of the world, which tells him that improving stories is something pilgrims tend to do. Hence past facts lead to present predictions. A further step in the meaning development is that towards a more intersubjective meaning involving the hearer and 'predictably' becomes 'as you may expect/may have expected'. Example (16) given above and repeated here with more context illustrates this sense:

(16) R: Do you want him to become Prime Minister

S. Of course I do

I think it would be wonderful <,>

Yes

I'd be terribly proud of him

Wouldn't anybody <,,> [broadcast news] <ICE-GB:S2B-003 \#135:1:S>

Example (16) is an extract from an interview with Mrs Heseltine about her husband, Michael Heseltine. She uses of course to present her positive reply to the question as 'to be expected'. This is made explicit in her following utterance 'wouldn't anybody'. In this way the speaker positions herself in a shared world of common values. This sense can be taken one step further into 'as everybody knows', and from there to the more intimate world of the interactants ('as you and I know'). In this sense of course ac- 
quires a predominantly interpersonal meaning. Example (20) illustrates 'as everyone knows', while (21) illustrates 'as you and I know'.

(20) The British obsession with class is quite remarkable

We persuade ourselves quite against all the available evidence that it perverts our social political and economic life

Foreigners believe this too

Here for example is Helmut Schmidt 's famous quote of nineteen seventy-five

He said as long as you maintain this damn class-ridden society of yours you will never get out of your mess

But Britain is more or less the same class structure as most advanced industrial societies a declining working class an expanding middle class although we display more social mobility than most others if the leading sociologists not usually Conservatives are to be believed

Now in spite of this the British class system is regarded as peculiar And it certainly would be peculiar if all the myths about it were actually true but of course they 're not

For example in nineteen eighty-four according to a Gallup poll seventy per cent of the British population claimed to be working class claimed not only that they were working class but their parents were working class

According to sociologists the percentage was at least twenty per cent less [broadcast talks] <ICE-GB:S2B-035 \#83:2:A>

In (20) the speaker presents the proposition that the myths about the British class society are untrue as shared knowledge.

(21) B: And and somebody else said well maybe that was a bit of a mouthful and you know try just an evening on your own together

A: Like skiing or something

Or a day trip

B: Yeah

Or something like that uhm <,>

so you know so far <laugh> none of those suggestions <unclearwords>

A: The other thing is uhm <,, > do you confide in her <,>

Does she feel excluded because you don't exactly confide in her

B: Well <,,> I don't 


\author{
But then <,> uh I haven't \\ I mean I never have <, > \\ and I' $m I$ ' $m$ rather scared that you know that would seem rather \\ artificial to her and as an attempt to win her over \\ and of course <,> you know she 's terribly alive to things like that \\ $<,>>$ hm [direct conversations] <ICE-GB:S1A-031 \#183:1:B>
}

In this casual conversation (21), the knowledge that 'she's terribly alive to things like that' is not generally known but belongs to the world of intimates. The meaning has evolved into 'as you and I know'. As a further step this intersubjective meaning gets further eroded into a marker of speech as interaction, where of course functions like you know (see Holmes 1988: 69). It seems to be developing this function in contexts where it co-occurs with other discourse markers and with disfluency markers. Example (22) illustrates this use:

(22) C: They th think different things are important $<,>$ and at the end of the day that makes the atmosphere of the <unclear-word> very different $<,>$ to a boys ' school <,>

D: Yes

But I mean

C: They 're they 're very upper class

I mean some of the things that get lost in boys' schools are are highlighted in a girls ' school

B: Uhm

D: Like <unclear-word>

B: $U h m$

C: $U h m<,>$

B: Pit bulls and anthems

I mean yeah

C: Oh yeah I mean it 's probably cos I mean you know they don't advocate the fact of course that you 're actually dealing with at the end of the day young girls or young boys

And they 've got different aspirations on what 's important as well

B: Uhm uhm [direct conversations] 〈ICE-GB:S1A-012 \#124:1:C>

Without wanting to claim that of course has become eroded and merely functions as a filler, we feel that it is important that it can occur in a context of hesitation markers and interpersonal hedges such as oh, yeah, I mean, probably, cos, you know, actually. 
What we see then is that the polysemy of PDE of course reflects a range of senses which can be put on a cline from more to less propositional, or from more to less objective. The comparative terms 'more to less' indicate that no instances are purely propositional or purely intersubjective: they are all layered. But some instances can be classified as predominantly one or the other, 'epistemic/evidential' or 'intersubjective'. Other instances are somewhere in between and indeterminate. Example (23) illustrates what we mean by 'indeterminate':

(23) I come back to uh Dumas every so often and read The Count of Monte Cristo or The Three Musketeers

Things like that

Things that have been with me I suppose since I was in my teens $<,>$

And and every so often I come back to them and uh and of course they get dog-eared and so on

so then then I scour the secondhand bookshops looking for decent copies of them <,> to uh bring my uh collection back to uh some decent state [direct conversations] <ICE-GB:S1A-013 \#71:1:E>

In (23) there is a clear sense of resultative of course : if one handles books very often they get dog-eared. A paraphrase with 'as a natural consequence' is possible here. On the other hand there is also a very clear interpersonal element, an appeal to the hearer to recognise the type of situation, to place it in what she knows about the world. The sense of inevitability is used to draw the hearer into a world of shared expectations, 'as you may expect', 'you know what I'm talking about'. We would therefore classify such instances as indeterminate.

A special type of usage which also combines the meanings 'inevitably' and 'shared expectations' is illustrated in (24) below.

(24) And literally she followed him down to 〈unclear-word> and the romance blossomed somehow

And another fellow who we cruelly nicknamed uh <unclear-word> foetus <, > laugh>

Foetus

that 's a very dreadful word

When he went over on a month 's trip to the Soviet Union

He was at Liverpool Poly to begin with but he was far too intelligent 
Apart from that he tried to smuggle this girl back Vera you know in the train com compartment where you 're supposed to shove the luggage

And of course Leda came up

This ha happened when my friend <unclear-word> was with him on a Sept September trip

And of course Leda came in and said

have you seen Richard <unclear-word>

And she said these two little heads were pro peeping down

from the top of the carriage [direct conversations] $<\mathrm{ICE}$ -

GB:S1A-014 \#162:1:B>

The fact that 'Leda came in' is presented as an inevitability because of what 'we know of the world': when things can go wrong they do go wrong. The sense of inevitability is not the result of some objective causal factor but is based on a subjective assessment of how things happen in this world. The tone of irony is the same as in the predictability sense which the modal would has developed in expressions such as Well he would say that, wouldn't he? In both cases a modal item has acquired a tone of irony to signal inevitability as a shared world-view ${ }^{5}$.

\subsection{Discourse status}

A second parameter which leads to two types of usage is 'discourse status.' This distinguishes between cases where of course confirms a previously brought up proposition (typically as a response marker) and where it modifies new information. Example (19) above is an instance of a response: the only new element in the speaker's utterance Of course I do is the confirmation of course, given in answer to a polar question. The 'given' information need not be present in a question but may also be in a previous statement, as in (25):

\footnotetext{
${ }^{5}$ The same development seems to have taken place in the case of no doubt in some contexts, where the speaker uses it as an ironic afterthought or response commenting on a proposition which s/he presents as to be expected (see Simon-Vandenbergen, 2007).
} 
(25) B: Now I think that over the years a breadth of experience outside politics and inside politics has equipped me to understand many of those concerns so I believe I can do it

But my colleagues will decide

I'm not going to breast beat about it

They will make a decision and I will abide by that decision

A: Of course

But of But of course of course of course they will and of course you will too

it 's self-evident [broadcast interviews] <ICE-GB:S1B-043

\#127:1:A>

In most cases, however, the speaker uses of course in an utterance which conveys new information. For example in (24) above the fact that 'Leda came in' has not been mentioned before in the conversation and is introduced by the speaker as new information.

\subsection{Heteroglossic functioning}

The term 'heteroglossia' has been borrowed from White (e.g. 2003), who uses the Bakhtinian term to refer to the view that all utterances take place in a context of other utterances, and that speakers in using language inevitably take a stance towards other viewpoints. White (2003) classifies semantic resources according to the type of positioning they convey. The function of the word of course is classified as 'concurrence', in that it represents "the textual voice as taking up some generally held position and thereby as concurring with the reader". The rhetorical function can also be termed "dialogical alignment" (White 2003: 269). A first basic distinction we noted in the data from this perspective is that between what we would call 'interior' and 'exterior' dialogue. In the former type the speaker is as it were weighing arguments for him/herself, and using of course to selfcorrect, to modify, to add another aspect, generally to signal a 'dip' in the argument. Again, there are various possibilities, which the following examples illustrate. Example (26) is a clear instance of engagement with an exterior voice:

(26) B: I am making the point that the Conservative Party in my judgement has three excellently qualified candidates and they will make 
a judgement as to which of those candidates most suit their preferences to be leader of their party

A: Sure but the reason why I invited you is because I thought you wanted to be at Morden and felt that the party ought to have you rather than them but uh of course it 's up to them [broadcast interviews] <ICE-GB:S1B-043 \#140:1:A>

In (26) speaker A expresses agreement with a viewpoint ('they will make a judgement') voiced by speaker B. Example (27) illustrates of course in a counter-argument against a viewpoint which the speaker does not share but which she herself voices in her discourse:

(27) A: The other thing is I suppose uhm $<,>$ uh that we this extraordinary notion <,, > that adolescents <,> should have their family unit as their centre of their life which of course children who go to boarding school don't have

but of course $<,>$ presumably if she is saying

no I don't want to go to boarding school

and yet you see she 'd have such a lot of fun there because she wouldn't have to think about you and Gavin and Bernard which is actually rather boring for her

She would have all her friends

Couldn't you send her uhm <,,> to a mixed school at sixteen like

King 's Canterbury where Fran 's going

or weekly

B: uhm uhm

Oh I see that yes uhm

uhm uhm uhm uhm [conversations] <ICE-GB:S1A-054 \#71:1:B>

Speaker A is here weighing pros and cons of sending B's daughter to boarding school as a solution for a problem B has brought up. The argument introduced by but of course is a counter-argument against the viewpoint expressed in A's own preceding utterance. The speaker thus positions herself against an alternative viewpoint which she introduces first to then argue against it. In example (28) there is no alternative voice which the speaker engages with except his/her own preceding statement. In such cases of course may announce a major or minor shift of topic.
B: I've never had one
D: Who you 


\author{
Nor've I \\ B: No you wouldn't Stuart because you don't pay tax <,> \\ But of course now they 're going to send everyone one aren't they \\ regardless of whether you $<,>>$ pay tax or not \\ E: Uh I don't know [direct conversations] <ICE-GB:S1A-007 \\ \#271:1:B>
}

One heteroglossic function which is frequently fulfilled by of course is 'countering'. 'Countering' is a general cover term for contexts in which speakers put propositions against other propositions. Arguments given by others or foreseen as possible arguments are 'disclaimed' (White's term 2003: 271) in various ways. White subsumes the strategy of disclamation and its subtype countering under the resources which contract the dialogue. His definition is the following:

\footnotetext{
"They [i.e. proclamations] stand beside a second grouping of resources which are even more contractive in that they entail the direct rejection or countering of a dialogically contrary position. They are the resources which I group under the general heading of DISCLAMATION which operate either as DENIAL (negation in the broadest sense) or as COUNTERING (various types of concessives, adversatives, and counter-expectancy)". (White 2003: 271)
}

The occurrences of of course in structural environments which express countering have been grouped into the following types:

(i) the collocation but of course: this is an instance of initial of course preceded by a coordinating conjunction;

(ii) but (...) of course: the occurrence of of course in a clause introduced by but where but and of course are separated by intervening constituents; (iii) whereas/although/while/without (...) of course: the occurrence of of course in a subordinate clause of contrast or concession;

(iv) of course (...) but : the occurrence of of course in a clause which is followed by another clause introduced by but.

Table 3 gives the frequency of these patterns in the total sample of 200 instances. 
Table 3. Frequency of occurrence of (i) but of course (ii) but (...) of course (iii) whereas/although/while/without (...) of course (iv) of course (...) but

\begin{tabular}{llllll}
\hline type (i) & type (ii) & type (iii) & type (iv) & total & $\begin{array}{l}\% \text { in the } \\
\text { sample }\end{array}$ \\
\hline 15 & 4 & 6 & 5 & 30 & $15 \%$ \\
\hline
\end{tabular}

Table 3 shows that $15 \%$ of all instances of of course occur in adversative or countering contexts ${ }^{6}$. The likelihood of certainty markers in such contexts has been noted in various studies (Holmes 1988; Downing 2001; Simon-Vandenbergen and Aijmer 2002/2003), and can be explained in terms of flouting of the Gricean maxim of Quantity (Grice 1975): since one is supposed to say only what one has evidence for, the addition of certainty markers is superfluous under 'normal' circumstances. If they are added they often signal the need for the speaker to persuade, to counter, to challenge, to dismiss. Certainty markers in general, then, are likely to be frequent in argumentative contexts where consensus cannot be taken for granted. Of course has the additional meaning of expressing shared knowledge, on top of its modal meaning of certainty, and this adds the 'complication' that we need to explain why and in what contexts speakers want to convey information which is already known and mark that information as such by the use of of course. Here are some examples of types (i) to (iv) in that order:

(29) George Bush in his inauguration speech said A president is neither prince nor Pope <,>

It was his way of saying that his approach to the job was not going to be grandiose or imperious

But of course the American people who love British Royals perhaps more than the Britons do <,> rather want that kind of figure and in the main they don't mind paying for it <,>

\footnotetext{
${ }^{6}$ In fact this is an underestimation of the real frequency because type (iv) is here limited to instances where the contrastive but-clause follows the of course-clause immediately, but such contrastive clauses may also be separated from the of courseclause by intervening clauses or the contrastive clause may not be introduced by an explicit but but nevertheless express a counter-argument. Such instances have, however, not been counted.
} 
At least they get to see some of what their money buys <,> [broadcast talks] 〈ICE-GB:S2B-021 \#1:1:A>

(30) And it 's an example of the uh hopelessness of the Europeans when faced with a crisis which is nothing to do with Europe but is outside the area of Europe because of course traditionally they have always been concerned with what happens within the Continent and left what happens outside the Continent to others including ourselves

But it 's of course one which doesn't alter the fundamental objections to political and economic and monetary union which uh have always been there [broadcast news] ICE-GB:S2B-013 \#44:1:E>

(31) And again my honourable friend doesn't understand the meaning of morality

Last week on a visit to Israel I found that the Israeli government was well aware of the dangers of her becoming militarily involved in the Gulf crisis

Uh

while she does of course have every right to defend herself will my honourable and learned friend urge the government of Israel to continue to show the considerable constraint which she has so far shown [parliamentary debates] 〈ICE-GB:S1B-060 \#84:1:A>

(32) Royalists say that the country makes a profit out of the monarchy Andrew Morton explains how this idea is mistaken <,, > <, > <, Those people were interviewed outside Buckingham Palace Like many others they believe that having a Royal Family is good for Britain 's tourist industry <,>

I couldn't find any real evidence that it is

Anyway other countries in Europe such as Austria and Switzerland make far more money out of tourism than we do and they are republics <,>

Of course republicanism isn't about the Royal Family failing as a tourist attraction but even so it is interesting to discover that it isn't a very great attraction <,>

The British Tourist Authority 's own figures show that the main tourist attractions have very little to do with living royalty [broadcast talks] <ICE-GB:S2B-032 \#33:1:A>

It can be seen that there are two main types of immediate contexts here, viz. contrastive and concessive. In both cases some proposition which is 
presented as shared knowledge is juxtaposed to another one. The types are repeated here for convenience:

(i) the collocation but of course: this is an instance of initial of course preceded by a coordinating conjunction. This type is illustrated in example (29).

(ii) but (...) of course: the occurrence of of course in a clause introduced by but where but and of course are separated by intervening constituents. This type is illustrated in example (30)

(iii) whereas/although/while/without (...) of course: the occurrence of of course in a subordinate clause of contrast or concession. This type is illustrated in example (31)

(iv) of course (...) but : the occurrence of of course in a clause which is followed by another clause introduced by but. This type is illustrated in example (32).

In types (i) and (ii) the speaker contrasts his/her statement, which is presented as shared knowledge, with a preceding one. In types (iii) and (iv) he/she backgrounds as self-evident an argument which is contrasted with his/her main argument. While the specific functions of of course may contextually vary (from authority to solidarity and from 'predictably' to 'as we all know'), the overall rhetorical function of of course is to express a consensual knowledge of some things in order to strengthen one's position in the dialogue. The meaning is very often a concessive one, with the speaker dismissing a proposition as 'true but irrelevant' or 'true but not the main point'. This is especially the case in type (iv), but the other types can also have the function of focusing on the 'main issue', as is very clearly and explicitly the case in example (2) (with reference to the fact that it does not 'alter the fundamental objections').

One important difference between the examples is the degree of foregrounding of the of course utterance. In some instances it is foregrounded (as in (1) and (2)), in others it is backgrounded (as in (3) and (4)). In types (i) and (ii) it is necessarily foregrounded because the but-clause follows the one it contrasts with; in type (iv) it is necessarily backgrounded because it precedes the but-clause.

\subsection{Pragmatic stance}

As pointed out by Holmes (1988), referred to in Section 2.1.2 above, of course may signal both authority and solidarity. By presenting a viewpoint as 'generally known' or 'self-evident' one may project an image of superi- 
ority as well as create an egalitarian relationship, depending on the heteroglossic function of the utterance and on contextual factors such as relationship between speakers and genre. In casual conversation the stance is generally one of solidarity and intimacy, with of course signalling a shared world, while in political colloquy the stance is generally authoritarian, with of course signalling superior knowledge. Example (21) above (from a conversation) illustrates the solidarity stance. Example (20) (from a broadcast talk) illustrates how of course projects authority. These examples are repeated here for convenience' sake.

(20) The British obsession with class is quite remarkable

We persuade ourselves quite against all the available evidence that it perverts our social political and economic life

Foreigners believe this too

Here for example is Helmut Schmidt 's famous quote of nineteen seventy-five

He said as long as you maintain this damn class-ridden society of yours you will never get out of your mess

But Britain is more or less the same class structure as most advanced industrial societies a declining working class an expanding middle class although we display more social mobility than most others if the leading sociologists not usually Conservatives are to be believed

Now in spite of this the British class system is regarded as peculiar And it certainly would be peculiar if all the myths about it were actually true but of course they 're not

For example in nineteen eighty-four according to a Gallup poll seventy per cent of the British population claimed to be working class claimed not only that they were working class but their parents were working class

According to sociologists the percentage was at least twenty per cent less [broadcast talks] <ICE-GB:S2B-035 \#83:2:A>

(21) B: And and somebody else said well maybe that was a bit of a mouthful and you know try just an evening on your own together

A: Like skiing or something

Or a day trip

<ICE-GB:S1A-031 \#178:1:B>

B: Yeah

Or something like that uhm <,> 
so you know so far <laugh> none of those suggestions <unclearwords>

A: The other thing is uhm <,, > do you confide in her <,>

Does she feel excluded because you don't exactly confide in her

B: Well <,, > I don't

But then $<,>$ uh I haven't

I mean I never have <, >

and I' $m$ I' $m$ rather scared that you know that would seem rather artificial to her and as an attempt to win her over

and of course $<,>$ you know she 's terribly alive to things like that $<$, , > uhm [conversations] <ICE-GB:S1A-031 \#183:1:B>

\section{Prosodic analysis}

\subsection{Prosodic prominence and separation}

If, as intonation theory claims, prosodic prominence is directly related to semantic weight, we would expect grammaticalised items to be infrequently stressed, just as function words are usually unstressed in English. Where layering occurs, i.e. where the grammaticalised form and the lexical form of a word or phrase co-exist in PDE, we would expect the latter to be more frequently stressed than the former. If our assumption is correct, namely that of course has gone further in the process of grammaticalisation, and now has discourse functions in which the lexical content has bleached further in comparison with its epistemic/evidential function, we would expect stressed tokens to be less frequent than unstressed tokens (other factors being equal). The distribution (Table 4) shows that this is indeed the case. ${ }^{7}$

\footnotetext{
${ }^{7}$ While stress is a binary feature in theory, the phonetic cues in naturally-occurring speech are not always clear-cut. Research has shown (Rietveld \& Gussenhoven 2003) that a high utterance-initial item can be perceived either as having a high pitch accent $\left(\mathrm{H}^{*}\right)$ or a high boundary tone $(\% \mathrm{H})$ (the former is maximally prominent and the latter minimally prominent). In the British system of intonation this distinction would be between a high pre-head syllable and a high onset. In some utterances in our data it was not possible to decide.
} 
Table 4. Distribution of of course tokens that are stressed, unstressed or indeterminate in status.

\begin{tabular}{llll}
\hline indeterminate & stressed & unstressed & total \\
\hline $16(8 \%)$ & $63(31.5 \%)$ & $121(60.5 \%)$ & $200(100 \%)$ \\
\hline
\end{tabular}

On this evidence, then, we have prosodic grounds for considering of course to have undergone a process of semantic weakening, and to be functioning at least in many cases as a discourse marker. Secondly, we consider the prosodic separateness or integration of of course. There are claims in the literature that discourse markers have a tendency to prosodic separation, reflecting their decreased syntactic integration in the utterance, but empirical studies show great variability. Our overview of the literature (2.2) shows that these opposing views are not necessarily mutually exclusive, but that the picture is more complex than would appear.

In our data we find, predictably, both separation and integration. There are, however, far more cases of integration than separation $(79.5 \%$ of all tokens) (see Table 5). This is, of course, consistent with the strong tendency for tokens to be unstressed, since separate tone units are assumed to contain at least one stressed syllable. It is not, however, consistent with the view that discourse markers tend towards increased prosodic separation.

Table 5. Distribution of of course tokens that are prosodically integrated, separate, or where this is indeterminate.

\begin{tabular}{llll}
\hline integrated & Separate & indeterminate & total \\
\hline $159(79.5 \%)$ & $35(17.5 \%)$ & $6(3 \%)$ & 200 \\
\hline
\end{tabular}

Theoretically (i.e. according to most models of intonational phonology) only the stressed tokens have the potential to have their own tone unit, and we would for the same reason expect all unstressed tokens to be integrated into a larger tone unit. The stressed tokens in this data are evenly divided between integration and separation. It must be remembered that there is potential for indeterminacy in identifying both prominence and boundaries, the choice of one often determining the choice of the other.

If we examine the co-occurrence patterns of the two parameters stress and separation (Table 6), we can say that more than half (56\%) of the tokens in the data are both unstressed and integrated. This contradicts suggestions that discourse markers tend to be prosodically separate, but supports the view that of course has a grammatical function rather than a lexical one. We will examine these patterns again below in relation to the various discourse functions described in Section 6. 
Table 6. Distribution of of course tokens according to the parameters stress and integration.

\begin{tabular}{|c|c|c|c|c|}
\hline & Stressed & Unstressed & Indeterminate & Total \\
\hline $\begin{array}{l}\text { Integrated } \\
\% \text { of integrated } \\
\% \text { of all tokens }\end{array}$ & $\begin{array}{l}33 \\
(21 \%) \\
(16.5 \%)\end{array}$ & $\begin{array}{l}112 \\
(70 \%) \\
(56 \%)\end{array}$ & 14 & 159 \\
\hline $\begin{array}{l}\text { Separate } \\
\% \text { of separate } \\
\% \text { of all tokens }\end{array}$ & $\begin{array}{l}26 \\
(74 \%) \\
(13 \%)\end{array}$ & $\begin{array}{l}8 \\
(23 \%) \\
(1 \%) \\
\end{array}$ & 1 & 35 \\
\hline Indeterminate & 4 & 1 & 1 & 6 \\
\hline total & 63 & 121 & 16 & 200 \\
\hline
\end{tabular}

To summarise, these overall results are consistent first with the notion that of course has undergone semantic bleaching and acquired a grammatical function (as reflected in the tendency to be prosodically non-prominent), and secondly with earlier observations that discourse markers can be both prosodically separate and prosodically integrated.

In the following we illustrate from the corpus how the parameters of stress and separation interact, dealing in turn with the four main cooccurrences: unstressed and integrated, stressed and integrated, unstressed and separate, stressed and separate.

Over half of the tokens $(56 \%)$ are unstressed and prosodically integrated, including initial, medial and final positions (33 a-c).

(33) Unstressed and integrated:
(a) How you $\vee$ fashion them of course | is the big big problem $<$ S1A-089 \#23:1:A>
(b) And of course \nobody will own $\vee u p<,>\langle$ S1A-059 \#125:1:B $>$
(c) a:::nd uh they 're very exciting of course $<\mathrm{S} 1 \mathrm{~A}-088$ \#68:1:A>

Those tokens that are stressed and integrated (34 a-c) tend to have a falling tone ${ }^{8}$.

(34) Stressed and integrated:

\footnotetext{
${ }^{8}$ Only 7 of a total of 63 stressed tokens have non-falling tones: 4 rise, 2 fall-rise and 1 low level.
} 
(a) Uhm a::nd of \course the \other part of the joke is that there is a sort of uhm <,> suggestion that the unity of the two is a mask as well $<,>$ a doubtful unity $\langle$ S2A-057 \#81:2:A $>$

(b) And what $\mathrm{VI}$ would do $\mid$ would ' not $^{9}$ be of $\backslash$ course| at the same level in any sense at all $\langle\mathrm{S} 1 \mathrm{~A}-024 \# 131: 1: \mathrm{B}\rangle$

(c) In the Vnicest possible \way of $\backslash$ course $\langle\mathrm{S} 1 \mathrm{~A}-085$ \#217:1:B>

Stressed and separate tokens in initial position (35) are typical of the prosodic separation frequently observed with other discourse markers. In initial position ( 35 a-e) they are followed, in most cases, by a pause (including $u h$ ). The tone choice is typical of reinforcing adverbials (e.g. obviously, clearly, definitely, certainly, without a doubt) - the sense of 'finality' or 'closure' being consistent with the exclusion of other possibilities entailed in the expression of certainty or reinforcement.

(35) Stressed and separate:

(initial)

(a) Of \course $\langle>|$ republicanism isn't about the Royal Family failing as a tourist attraction $\langle\mathrm{S} 2 \mathrm{~B}-032$ \#39:1:A $>$

(b) But of \course | Alexander came along after classical ballet $\langle\mathrm{S} 1 \mathrm{~A}-045$ \#38:1:B >

(c) But of \course uh $\mid$ foreign $\bigvee$ governments uh $\mid$ warning their citizens have to take wider things into ac into account $<\mathrm{S} 2 \mathrm{~B}-$ $012 \# 136: 1: G>$

(d) Of \course | <,> you are entitled to draw conclusions <,> from the $\langle$,$\rangle uh \langle$,$\rangle evidence <,\rangle,\langle\mathrm{S} 2 \mathrm{~A}-061$ \#17:1:A $\rangle$

(e) Now uh <,> of \course <,> uh 'you 've Vheard <,> uh these uh $<,>$ uh words read out $<,>$ al already <,> uh more than once $<,>\langle\mathrm{S} 2 \mathrm{~A}-061 \mathrm{\# 88:1: \textrm {A } \rangle}$

(final)

(f) Well we 're Nnot going to force them to /take it $\mid$ of \course $<$ S2B-035 \#45:1:A >

(g) No not a \word $\mid$ of $\backslash$ course $<\mathrm{S} 1 \mathrm{~A}-069$ \#104:1:B> (medial)

(h) As soon as it is possible to say something more concrete about that $\mid$ then of $\bigvee$ course $\mid$ we will do so $\langle\mathrm{S} 2 \mathrm{~B}-014$ \#42:1:B>

(i) The buildings as we have them $\mid$ of $\backslash$ course $\mid$ Vare later $<\mathrm{S} 2 \mathrm{~A}-$ 060 \#17:1:A>

\footnotetext{
${ }^{9}$ The `symbol indicates here a high onset that displays little pitch movement.
} 
Unstressed and separate tokens are anomalous: according to the rules of prosodic phonology, unstressed tokens could not be other than prosodically integrated, given that the presence of a tone (pitch accent) is a defining characteristic of a tone unit. ${ }^{10}$ However, a number of initial unstressed tokens in our data are separated by a pause from the rest of the utterance (36 a-c).

(36) Unstressed and separate:

(a) And of course $\langle>|$ a late date is suggested by the fact that Malachi is the last of the prophets <S1B-001 \#146:1:A>

(b) but of course <,> prVesumably | if she is saying <S1A-054 \#65:1:A>

(c) Of 'course <>it 's it 's en\tirely possible to waste your ent en\tire working \day on it $\langle\mathrm{S} 1 \mathrm{~A}-015$ \#19:1:A $\rangle$

(d) and of course <,> you know | she 's terribly Valive to things like that $<,,>$ uhm $<$ S1A-031 \#187:1:B>

This anomaly is already well documented in the intonation literature (e.g. Cruttenden 1997). A pause is assumed to be a strong indication of a prosodic boundary, and by this definition these tokens are clearly separate, but a separate tone unit is required to contain an accented syllable, which is not present here. The conflict thus lies between external (boundaries) and internal (accented syllables) definitions of tone units. If this is a problem, however, it is more a problem for generative phonology than for the study of discourse. ${ }^{11}$ Such pauses are quite systematic in some contexts, even in formal read-aloud prose. ${ }^{12}$ It is entirely consistent with observations of other discourse markers (well, now, so) that they can be followed by a pause despite being short and unstressed. From a CA perspective (see Sacks et al. 1974: 719-720) these can be seen as projecting a turn and claiming the floor while allowing time to formulate an utterance. ${ }^{13}$ This

\footnotetext{
${ }^{10}$ Variously called tone groups, tone units, intonation units, intonation phrases etc.

${ }^{11}$ An unaccented discourse marker followed by a pause was observed often enough by Chafe (1994) for him to see this as what he calls a 'regulatory' tone unit. By distinguishing between different kinds of unit he dispenses with the anomalies arising from more formal intonational phonology.,

${ }^{12}$ We refer e.g. to the pause that often precedes a final reporting clause $(\ldots<>$ he said) even though it contains no accented material.

${ }^{13}$ We are grateful to an anonymous reviewer for drawing our attention to this.
} 
phenomenon does highlight, however, the lack of specificity in some comments on prosody in the discourse literature. The binary distinction between integration and separation does not take into account indeterminacy nor the fact that temporal and melodic separation/integration have to be specified separately. In other words, when a discourse marker is referred to as 'prosodically separate', we do not know whether it is unstressed followed by a pause, or stressed and carrying a tonal contour followed by a boundary (including but not necessarily a pause). Formal intonational phonology can account for the latter but not for the former.

\subsection{Prosodic realisation and semantic meaning}

In this section we consider the extent to which prosodic realisation correlates with meaning. We have already suggested that the high frequency of unstressed tokens suggests a high degree of grammaticalisation. Here we attempt to relate the accentual status of tokens to an independently judged degree of semantic weight. Despite retaining a consistent underlying core meaning, of course can convey anything from this is a natural consequence to you/we know this. (Section 5.2) In other words, some uses are clearly epistemic in that they express the speaker's stance towards the truth of proposition, while in others the meaning has become more opaque ${ }^{14}$ to convey little more than 'shared knowledge'. In some cases of course seems to perform some "routine (organizational) task in interaction" which discourse markers such as I think, I mean, and you know also perform in some contexts (Kärkkäinen 2003: 172). In between these two extremes there are many shades and gradations, and these will be discussed later, but for practical purposes we have divided this continuum into three broad categories: epistemic, shared knowledge and indeterminate. Intonation theory, as discussed above, would predict that those items at the transparent end of the spectrum, and therefore having greater residual semantic weight, are more likely to be stressed than those at the other extreme.

The data confirms this prediction (see Table 7). A chi-squared test was carried out to ascertain whether there was an association between meaning and accentual status. The tokens whose accentual status could not be decided (first column) were omitted from the analysis. The test showed a very strong association between meaning and accentual status (chisquared $=22.3, \mathrm{df}=2, \mathrm{p}<0.001)$. There is a clear trend showing that on the

\footnotetext{
14 Juliane House (1989: 104) uses 'opaque' to mean 'non-transparent and having highly negotiable illocutionary force'.
} 
continuum from interpersonal meaning to literal meaning ('shared knowledge' > 'indeterminate' > 'epistemic') the probability increases that the token will be stressed, and conversely, as the literal meaning fades, the probability increases that the token will be unstressed.

Table 7. Distribution of of course tokens according to accentual status and meaning

\begin{tabular}{|c|c|c|c|c|c|c|}
\hline \multirow[t]{2}{*}{ Stress } & \multirow[t]{2}{*}{ Indeterminate } & \multicolumn{2}{|c|}{ Stressed } & \multicolumn{2}{|c|}{ Unstressed } & \multirow[t]{2}{*}{ Total } \\
\hline & & $\mathrm{Ob}$ & /expected & $\mathrm{Obs}$ & /expec & \\
\hline $\begin{array}{l}\text { Shared } \\
\text { knowledge }\end{array}$ & 3 & 11 & 19.7 & 47 & 38.3 & 61 \\
\hline Indeterminate & 9 & 10 & 16.3 & 38 & 31.7 & 57 \\
\hline Epistemic & 5 & 41 & 26.1 & 36 & 50.9 & 82 \\
\hline Total & 17 & 62 & & 121 & & 200 \\
\hline
\end{tabular}

These broad overviews of the data do not take into account utterance position, nor do they distinguish between the various discourse functions of of course. We also acknowledge the inevitable difficulty of forcing gradient data into fixed categories, but by basing our interpretations on the written transcripts alone we have at least endeavoured to avoid circularity. The results support claims that of course has undergone grammaticalisation, functioning chiefly as a discourse marker (with both textual and interpersonal functions), while still having the potential to express more transparent, epistemic meaning, closer to the original core meaning. However, despite the evidence for a relationship between stress and semantic weight, we will see from the examples below that there are other parameters e.g. information status and pragmatic function, that make it impossible to expect a one-to-one relationship between prosodic realisation and any one parameter.

\subsection{Prosody and discourse status}

The status of the information modified by of course, as set out in 6.3, can be either given or new in conjunction with previously given (or otherwise readily accessible) information and the of course serves to emphasise its certainty or self-evident truth. In these cases the of course carries by default nuclear tone, since the given information is either omitted or deaccented, and there is no other material available to carry the nucleus ( 37 $\mathrm{a}-\mathrm{c})$. 
(a) Vwin $\mid$ of $\bigwedge$ course I'm running to win $\langle$ S1B-043 \#21:1:B>

(b) Of \course I need a longer break from Darryl <S1A-011 \#153:2:A>

(c) Well of $\backslash$ course it is $\mid$ [but uh] $\langle\mathrm{S} 1 \mathrm{~A}-023$ \#41:1:A $\rangle$

To treat the given proposition as 'natural' or 'predictable' in this way, undermines to some extent the previous speaker's justification in making it in the first place, having the sense of 'you should know that'. It is therefore not simply a function of information structure, but has a marked attitudinal meaning, the nuances of which will depend on other contextual parameters.

\subsection{Prosody and heteroglossia}

The attitudinal effect ascribed to the above examples also reflects their dialogic function (heteroglossia). In the simplest cases, the of course utterance is a response to an actual previous question or statement. Sometimes, however, the exterior 'voice' being responded to is hypothetical, allowing the speaker to pre-empt and dismiss an unspoken objection. In this case the hypothetical objection must be introduced to the discourse by the (real) speaker, but at the same time treated as 'given' (and thus already dismissed). This occurs in the following example:

(38) A: Liberal Democrat leader Paddy Ashdown says that civilian deaths are regrettable but he says it would be wrong to condemn the U S military commanders for what appears to have been an error

B: It is not as some of us have perhaps more comfortably believed a transcontinental video game in which nobody gets hurt

This was clearly a mistake

It 's not part of the policy

And these mistakes happen in war

Of course if there are lessons to be learnt we should be learning them

But it would be wrong for politicians to second-guess the military who are taking the tough decisions to win this war from four thousand miles away [broadcast news] 〈ICE-GB:S2B-016 \#93:3:B> 
In extract (38) the speaker is countering the condemnation of the US military commanders for civilian deaths, by first of all stating that these deaths were not "part of the policy" and that such mistakes are inevitable (these mistakes happen in war). The hypothetical objection that 'there are lessons to be learnt' is then treated as leading to a self-evident conclusion ( $O f$ course [...] we should be learning them ). By presenting the conclusion as self-evident, it is backgrounded as 'non-new'. The main point of the speaker's answer is in the following clause, introduced by but, which denies that the military should be condemned. The prosodic challenge here is to simultaneously introduce a new proposition 'learning lessons' and treat it as given (a mutual belief). The speaker realises the utterance as follows:

\section{Of \course if there are lessons to be /learnt | we should be Vearning them}

The absence of any accent on lessons suggests that the notion is already accessible. The high terminal on learnt is consistent with grammatical subordination of an if-clause, but of possible choices (level, fall-rise, high rise, low rise) at this point, the low riseis psychologically the least salient (Cruttenden 1997: 43), adding to the impression of 'given information'. ${ }^{15}$ Such countering appears more effective and authoritative when of course is stressed, as if responding energetically to a real dissenting voice, and thus has a stronger dialogic effect. This is a feature of a persuasive rhetorical style, typical of political debate, and sets up an asymmetrical power relationship between speaker and hearers (or silent interlocutors).

The third type of heteroglossic response is ratiocinative, in other words it is part of the process of developing one's own argument in real time, and the 'voices' reflect different aspects of one's own reasoning. This kind of thinking aloud is common in unplanned discourse, reflected in a number of connective strategies (but on the other hand, but then again, mind you, on balance though). The prosodic strategy is different from the cases described earlier, because the function is contrastive rather than countering, and may simply signal a shift in the discourse. We therefore find a number of cases where the of course is unstressed $(39 a, b)$.

\footnotetext{
${ }^{15}$ An anonymous reviewer points out, rightly, that a rise on a subordinate clause in this position is predictable. However, this subordinate clause does not have its own tone group, as one would expect, but is integrated prosodically with the preceding of course. This enhances the impression that it is being treated as given information.
} 
(a) But of course Vnow | they 're going to send everyone one aren't they regardless of whether you <,,> pay tax or not $<$ S1A-007 \#272:1:B>

(b) but of course <,> prVesumably | if she is saying <S1A-054 \#65:1:A>

If a stressed token occurs in this context it suggests less an emphatic countering of an objection (as in the previous example) and more a strong shift in the discourse - either a temporary digression, in other words a move to a different level in the hierarchical structure of the discourse, or a linear move from one (sub)topic to another. Example (23) is an instance of this: (so of course they get dog-eared) on the one hand this simply expresses the natural consequence of frequent reading, but at the same time it creates a link to a new part of the narrative (so then I scour the second-hand bookshops). The and uh and sequence is symptomatic of a hesitant planning phase, and is typical of topic transitions in spontaneous narrative where a slowing down is followed by an acceleration into the next section - a change in tempo reflected in the reduced form of of course ('course). This further supports our assumption that the stress on of course signals a shift rather than emphasising the fact that books get dog-eared if read frequently.

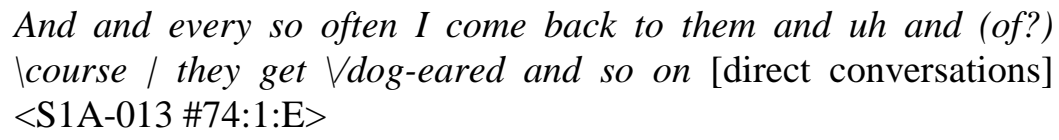

\subsection{Pragmatic stance}

We have shown that a common function of of course is to express shared knowledge, either with the purpose of exerting power or in order to express solidarity. Where an authoritative tone is intended, we often find emphatic use of of course. Where symmetry and closeness are the goal, however, there appears to be little need to focus on the of course since there is no argument to be countered and no dissenting voice to be answered. Thus we find tokens used in this way are usually minimally prominent, reflecting also the fact that the core meaning is only minimally present.

The expression of solidarity has different functions in different contexts, depending on such factors as the roles of the interactants and the aims they want to achieve in the interaction. In a teaching situation the 
word can function as a way of including the learners and their knowledge. In example (41) this attempt at inclusion is conveyed both by of course and by the tag question doesn't he.

(41) And O\thello of course | calls on uh Desdemona 's Vather doesn't he $\mid$ and then he tells her the story of his life [direct conversations] $<$ S1A-020 \#211:1:B>

In a football commentary, example (42), the of course serves to suggest to a radio audience that they are experts, sharing detailed knowledge with the commentator, who is filling in with what 'everyone knows':

(42) United on a Vgood run at the moment | whereas VRangers of course | have been Istruggling in the First Di/vision [spontaneous commentaries] <S2A-003 \#56:1:A>

In the special context of a radio interview, the interviewee is often obliged to 'tell' the interviewer what they already know, because the interview has been prepared in advance. What is new to the radio audience is shared knowledge between the interlocutors. The dilemma for the speaker can be reflected in the use of of course, signalling complicity with the interviewer while performing the information as if new for the audience. In example (43) the late Archbishop of Canterbury, Robert Runcie, talks about his mother, and the fact that she had been a hairdresser. There is little residual meaning here of 'a natural course of events', since our knowledge of the world around us, or at least that part of the world that contains Anglican archbishops, does not normally permit us to predict the occupation of their mothers:

Uh but uh she Vhad been of course uhm <,> a a Vhairdresser on an ocean liner $<$ S1B-041\#147>

A similar interview situation elicited examples (44 a,b), in which the information is in no way predictable but is marked as knowledge shared by the interlocutors:

(44) (a) hhh of course I've $\wedge$ been a congregational /rabbi $<$ S1B047\#028>

(b) but then of course | I lwent into <>secular phi /losophy $<$ S1B-047\#056> 
In this special situation, where a speech situation involves multiple addressees, the use of of course is a way of providing information that is new to one part of the audience and known to the other.

\section{Conclusion}

Our findings relate to three main areas of inquiry: structure, meaning and use, and prosody. In structural terms our data showed a clear preference for of course to occur in initial position as part of the thematic material, followed by medial position, where of course is post-thematic and serves to highlight the theme. In terms of meaning, we found strong evidence of grammaticalisation with more literal meanings ('as a natural consequence') occurring alongside subjective ('predictably') and intersubjective developments ('as you may expect' or 'as you and I know'). In a number of cases, the tokens have acquired a routinised pragmatic function and operate as an interactive marker. From a rhetorical perspective, the subjective and intersubjective meanings of of course are exploited dialogically, including conceding or countering other points of view. Depending on context, this function can reinforce solidarity, as for example in casual conversation, but also express power, as for example in political debate, where dissenting voices are dismissed in favour of one's own argument.

Finally, on the basis of theories of intonational meaning, we predicted that semantic change involving a loss of semantic weight in favour of pragmatic meaning will also involve a loss of prosodic prominence. This is borne out by the data, which shows a statistically significant association between prosodic prominence and meaning. Of course as a grammaticalised/ pragmaticalised item may be said to be unstressed in its unmarked realisation, although the constraints of information structure, text structure or dialogic demands can require it to be brought into focus. In this respect the prosodic patterns found in our data, though diverse, are all consistent with a polysemous pragmatic marker.This study also has broader implications for the study of grammaticalisation. A usage-based model of language (e.g. Bybee 2001) argues that patterns of change are affected by frequency of use: high frequency items can be vulnerable to phonological change involving attenuation of form, and frequency-induced habituation can lead to a loss of semantic meaning. Our corpus-based approach, therefore, acknowledges the importance of quantitative (frequency) information to complement more qualitative analyses. Secondly, since the processes asso- 
ciated with grammaticalisation are in part phonological, it makes sense to focus on speech rather than writing. Phonological reduction typical of grammaticalisation has so far only been described in segmental terms, and prosodic phenomena ignored, but the reduction of articulatory gestures is clearly a function of the prosodic realisation of the word or phrase in question: a word that is unstressed has shorter duration than its stressed counterpart, leaving less time for careful articulation. Thus articulatory gestures may overlap or fail to meet targets. There are obvious problems associated with studying prosody from a historical perspective, but we believe that synchronically co-occurring prosodic patterns may reflect different stages in the grammaticalisation process. If semantic change and phonological change are related, our view of such processes can only be enhanced by the study of contemporary speech and its prosodic characteristics.

As we reported, there has been little systematic study of the prosody of discourse markers in general. While we, too, have focused on a single specific marker, we believe that our study has broader implications for the study of discourse markers in general. Most importantly, it is clear that there can be no single prosodic pattern that is 'the prosody of discourse markers'. We know, for example, that tone choice is determined inter alia by position in an utterance and by meaning. Thus, falling tones conveying 'finality or closure' are not surprisingly more commonly associated with initial adverbials that reinforce rather than limit a proposition (compare certainly, of course with possibly, apparently), thus overriding another constraint, namely to use a non-final, or 'open' tone (e.g. a rise) to indicate that the utterance is incomplete. Accent status is also constrained partly by context, partly by morphology, partly by information structure (given new) and by text structure. Finally, phrasing (status in a tone group) may depend on speech style, situation, or on the role of the speaker in terms of power, knowledge or rhetorical goals. In sum, prosodic choices - segmentation, accent placement and tone choice - convey abstract meanings that can be related only indirectly to lexical items, and are motivated in part by convention, but largely by the often conflicting demands and constraints of the semantic, pragmatic and discoursal functions that discourse markers fulfil. 


\section{References}

Aijmer, Karin

2000 English Discourse Particles: Evidence from a corpus. Amsterdam: Benjamins.

Aijmer, Karin and Anne-Marie Simon-Vandenbergen (eds.)

2006 Pragmatic Markers in Contrast. Studies in Pragmatics 2. Amsterdam: Elsevier.

Aijmer, Karin, Ad Foolen and Anne-Marie Simon-Vandenbergen

2006 Pragmatic markers in translation: a methodological proposal. In $\mathrm{Ap}$ proaches to Discourse Particles. Kerstin Fischer (ed.).Studies in pragmatics 1. Amsterdam: Elsevier, 101-114.

Altenberg, Bengt

1987 Predicting text segmentation into tone units. In Corpus Linguistics and beyond. Willem Meijs (ed). Amsterdam: Rodopi, 49-60.

1990 Automatic text segmentation into tone units. In The London Lund Corpus of Spoken English: description and research. Jan Svartvik

Anon (ed.). Lund, Sweden: Lund University Press, 287-323.

1989 Oxford English Dictionary, 2nd ed. Oxford: Clarendon Press.

Barth, D. and E. Couper-Kuhlen

2002 On the development of final though: a case of grammaticalization? In New Reflections on Grammaticalization. I. Wischer and G. Diewald (eds.). International Symposium, Potsdam, 17-19 June, 1999. Typological Studies in Language 49. Amsterdam: Benjamins, 345-361.

Biber,D., Johansson, S., Leech, G., Conrad, S. and E. Finegan

1999 Longman grammar of spoken and written English. London: Longman.

Bolinger, Dwight

1989 Intonation and its Uses. London: Edward Arnold.

Bybee, Joan

2001 Phonology and Language Use. Cambridge: Cambridge University Press.

Chafe, Wallace

1994 Discourse, consciousness and time. Chicago: University of Chicago Press.

Cruttenden, Alan

1986 Intonation. Cambridge: Cambridge University Press.

Diewald, Gabriele

2006 Discourse particles and modal particles as grammatical elements. In Approaches to Discourse Particles. Kerstin Fischer (ed.). Studies in Pragmatics 1. Amsterdam: Elsevier, 403-425.

Erman, Britt and Ulla-Britt Kotsinas 
1993 Pragmaticalization: the case of ba' and you know. Studier I Modern Språkvetenskap. Acta Universitatis Stockholmiensis, New Series 10, 76-93.

Ferrara, Kathleen W.

1997 Form and function of the discourse marker anyway: implications for discourse analysis. Linguistics 35: 343-378.

Fischer, Kerstin (ed.)

2006 Approaches to Discourse Particles. Studies in pragmatics 1. Amsterdam: Elsevier.

Grice, Paul

1975 Logic and conversation. In Syntax and semantics 3: Speech acts.

Peter Cole and Jerry Morgan (eds). New York: Academic Press, 4158.

Günther, S.

1999 Entwickelt sich der Konzessivkonnektor obwohl zum Diskursmarker? Grammatikalisierungstendenzen im gesprochenen Deutsch. Linguistische Berichte 180, 409-446.

Halliday, M. A. K. and R. Hasan

1967 Cohesion in English. London: Longman.

Halliday, M.A.K. and C. Matthiessen

2004 An Introduction to Functional Grammar. Third edition. London: Arnold.

Heine, B., U. Claudi and F. Hünnemeyer

1991 Grammaticalization: A conceptual framework. Chicago: University of Chicago Press.

Hirschberg Julia and Litman D.

1993 Empirical studies on disambiguation of cue phrases. Computational Linguistics 19: 501-30.

Holmes, Janet

1985 Functions of you know in women's and men's speech. Language in Society 15, 1-22.

1988 Of course: a pragmatic particle in New Zealand women's and men's speech. Australian Journal of Linguistics 2: 49-74.

Hopper, Paul J. and Elizabeth Closs Traugott

2003 Grammaticalization. Cambridge: Cambridge University Press.

Horne, M., Hansson, P., Bruce, G., Fried, J. and M. Filipsson

2001 Cue words and the topic structure of spoken discourse: the case of

Swedish men. Journal of Pragmatics 33: 1061-1081.

Kärkkäinen, Elise

2003 Epistemic Stance in English Conversation. Amsterdam: John Benjamins.

Lehmann, Christian

1995 Thoughts on Grammaticalization. München: LINCOM EUROPA.

Lewis, D. M. 
2003 Rhetorical motivations for the emergence of discourse particles, with special reference to English of course. In Particles, T. van der Wouden, A. Foolen and P. Van de Craen (eds.). 79-91. Belgian Journal

Lima, J. Pinto de of Linguistics vol. 16. Amsterdam/Philadelphia: John Benjamins.

2002 Grammaticalization, subjectification and the origin of phatic markers. In New Reflections on Grammaticalization. I. Wischer and G. Diewald (eds.). International Symposium, Potsdam, 17-19 June, 1999. Typological Studies in Language 49. Amsterdam: Benjamins, 363378.

Meyer, Charles. F.

1986 Punctuation practice in the Brown Corpus. ICAME news 10: 80-95.

Nelson, Gerald, Sean Wallis and Bas Aarts

2002 Exploring Natural Language: Working with the British Component of the International Corpus of English. Amsterdam: John Benjamins.

Pierrehumbert, Janet and Julia Hirschberg

1990 The meaning of intonational contours in the interpretation of discourse. In Intentions in Communication. P.R. Cohen, J. Morgan and M.E. Pollack (eds.).Cambridge Ma., London: MIT Press.

Quirk, Randolph, Sidney Greenbaum, Geoffrey Leech and Jan Svartvik

1985 A comprehensive grammar of the English language. London: Longman.

Rietveld, Toni and Carlos Gussenhoven

2003 The perception of preheads as accents. In Proceedings ICPhS, Barcelona. 759-62.

Simon-Vandenbergen, Anne-Marie

1992 The interactional utility of of course in spoken discourse. Occasional Papers in Systemic Linguistics 6: 213-226.

2007 No doubt and related expressions: a functional account. In The English clause. Mike Hannay and Gerard J. Steen (eds.). Amsterdam and Philadelphia: John Benjamins.

Sacks, Harvey, Emanuel A. Schegloff, Gail Jeffersone

1992 A simplest systematics for the organization of turn-taking for conversation. Language 50: 696- 735.

.Simon-Vandenbergen, Anne-Marie and Karin Aijmer

2003/2004The expectation marker of course. Languages in Contrast 4(1): 1343.

Simon-Vandenbergen, Anne-Marie, Peter White and Karin Aijmer

forthc. Presupposition and 'taking-for-granted' in mass communicated political argument. An illustration from British, Flemish and Swedish political colloquy. In Media Discourse from an Intercultural Perspective. G.Lauerbach and A. Fetzer (eds.). Studies in Pragmatics. Amsterdam: Elsevier.

Stenström, Anna-Brita 
1990 Adverbial commas and prosodic segmenatation. In The London Lund Corpus of Spoken English: description and research. Jan Svartvik (ed.). Lund: Lund University Press, 253-266.

Thompson, Geoff

2004 [1996] Introducing Functional Grammar. London: Arnold.

Traugott, Elizabeth Closs

1989 On the rise of epistemic meanings in English: an example of subjectification in semantic change. Language 65: 31-55.

1997 [1995]The role of the development of discourse markers in a theory of grammaticalization. Paper presented at ICEHL XII, Manchester 1995. Accessed on the internet .http://www.stanford.edu/ traugott/papers/discourse.pdf.

Traugott, Elizabeth \& Richard B. Dasher

2002 Regularity in semantic change. Cambridge: Cambridge University Press.

Wennerstrom, Ann

2001 The Music of Everyday Speech: Prosody and Discourse Analysis. Oxford: Oxford University Press.

White, Peter

2003 Beyond modality and hedging: a dialogic view of the language of intersubjective stance. Text 23(2): 259-284.

Wichmann, Anne

1998 Using intonation to create conversational space: projecting topics and turns. In Explorations in Corpus Linguistics. Antoinette Renouf (ed). Rodopi: Amsterdam, 217-232.

2000 Intonation in Text and Discourse. Longman: London. 